\title{
Forced oscillation technique for the evaluation of severe sleep apnoea/hypopnoea syndrome: a pilot study
}

\author{
J.R. Badia*, R. Farré**, J.M. Montserrat*, E. Ballester*, L. Hernandez*, M. Rotger**, \\ R. Rodriguez-Roisin*, D. Navajas**
}

Forced oscillation technique for the evaluation of severe sleep apnoea/hypopnoea syndrome: a pilot study. J.R. Badia, R. Farré, J.M. Montserrat, E. Ballester, L. Hernandez, M. Rotger, R. Rodriguez-Roisin, D. Navajas. (OERS Journals Ltd 1998.

ABSTRACT: The forced oscillation technique (FOT) is a noninvasive method of potential clinical interest for quantitatively assessing airway mechanics during sleep. We investigated the applicability of FOT as a diagnostic tool for noninvasive assessment of airflow obstruction in patients with sleep apnoea/hypopnoea syndrome (SAHS) during sleep.

In seven patients previously diagnosed with severe SAHS (mean \pm SD apnoea/ hypopnoea index (AHI) 67 \pm 14 ) we performed a full polysomnography (PSG) together with on-line measurement of respiratory impedance $(|Z|)$ using FOT. For each patient we determined: 1) number of respiratory events conventionally detected by full PSG, those obtained by FOT and their degree of concordance; and 2) the characteristics and values of $|Z|$ during the respiratory events. FOT was well tolerated and easily applied in conjunction with a conventional sleep setup.

The mean number of respiratory events' $h^{-1}$ detected by PSG and FOT were $55 \pm 16$ and 58 \pm 17 , respectively, with a strong concordance. $|Z|$ increased from a baseline of $11 \pm 4$ to $50 \pm 20 \mathrm{cmH}_{2} \mathrm{O} \cdot \mathrm{L}^{-1 \cdot} \cdot \mathrm{s}$ during apnoea (mean $\pm \mathrm{sD}$ ). In all but one patient intermittent increases of $|Z|$ occurred immediately before each obstructive apnoea. In four patients, the increases of $|Z|$ developed at end-expiration whereas in two others occurred during inspiration. During hypopnoea most of the patients showed decreases of $|Z|$ during expiration.

In conclusion, forced oscillation technique can be used as a noninvasive and complementary tool for the diagnosis of respiratory events and provides an on-line quantitative approach for continuous monitoring of airflow obstruction during sleep in patients with sleep apnoea/hypopnoea syndrome. Eur Respir J 1998; 11: 1128-1134.

\begin{abstract}
*Servei de Pneumologia i Al.lèrgia Respir-atòria, Departament de Medicina, Hospital Clínic, **Laboratori de Biofísica i Bioenginyeria, Facultat de Medicina, Universitat de Barcelona, Barcelona, Spain.
\end{abstract}

Correspondence: J.M. Montserrat

Servei de Pneumologia i Al.lèrgia Respiratòria

Hospital Clínic

Villarroel 170

08036 Barcelona

Spain

Fax: 3432275454

Keywords: Airway obstruction

obstructive sleep apnoea

respiratory impedance

sleep studies

Received: May 261997

Accepted after revision November 111997

Supported by grants from Fondo de Investigaciones Sanitarias (FIS) 97/0422, SEP$\mathrm{AR} / 97$ and Comision Interministerial de Ciencia y Tecnologia (CICYT): SAF 960076.
Patients with obstructive sleep apnoea/hypopnoea syndrome (SAHS) experience repeated episodes of increased upper airway resistance leading to profound disturbances in sleep architecture and arterial blood gases [1, 2]. Repeated inspiratory efforts occur during an obstructive sleep apnoea until arousal ensues and airway patency is restored [3]. The increased upper airway resistance in patients with SAHS can be assessed indirectly by the analysis of different signals, such as the time profile of the inspiratory flow signal, the noise of snoring, the use of strain gauges or inductance plethysmographs [4-7]. However, as the recent description of the upper airway resistance syndrome has pointed out [8], the classical noninvasive techniques previously described are unable to detect the full range of respiratory-related flow events that occur throughout the night. A more direct quantitative approach is the recording of the inspiratory driving pressure by means of an oesophageal catheter [8-10], although this has limited applicability in routine studies. Accordingly, methods to quantify changes in airway resistance noninvasively are required.
The forced oscillation technique (FOT) provides a noninvasive method to quantify and assess the degree of airway obstruction, thus avoiding the need for a measurement of oesophageal pressure. It consists of superimposing on spontaneous breathing a small pressure oscillation through a nasal mask attached to the patient [11]. Respiratory impedance $(|Z|)$ is derived from pressure and flow signals recorded at the nasal mask. Because patient co-operation is not required the technique can be applied during sleep. The potential applicability of FOT to assess airway obstruction in SAHS studies has recently been substantiated in a model study [12]. $|Z|$ measured by FOT was found to be an accurate index of overall airflow obstruction [12]. The aim of the present study was to ascertain whether FOT is applicable in human diagnostic sleep studies for noninvasive assessment of airway obstruction in SAHS patients. Specifically, we were interested in testing whether respiratory events detected by FOT corresponded with those recognized by more conventional approaches. Furthermore, we wished to establish whether the FOT could be an adequate method continuous monitoring of airway mechanics dur- 
ing sleep. Consequently, we chose for study a group of patients with severe SAHS.

\section{Methods}

\section{Subjects}

Seven male subjects with polysomnographically documented SAHS (table 1) not previously treated with continuous positive airway pressure (CPAP) were evaluated during "nap" polysomnography with additional on-line measurement of $|Z|$ using the FOT. The subjects had no other current medical problems and routine pulmonary function tests showed no evidence of airway obstruction. This study was approved by the Human Ethics Committee of the Hospital Clinic and informed written consent was obtained from all, subjects prior to the study.

\section{Polysomnography (PSG)}

PSG was performed in the usual manner, including continuous monitoring of the electroencephalogram (EEG) (C4/A1, C3/A2), chin electromyogram (EMG) and electrooculogram (EOG) for sleep staging according to standard criteria [13]. Arterial oxygen saturation $\left(\mathrm{Sa}_{\mathrm{a}} \mathrm{O}_{2}\right)$ was measured continuously with a finger probe using a pulse oximeter (504; Critical Care Systems Inc., Waukesha, WI, USA). Ribcage and abdominal motion were monitored by bands placed over the thorax and abdomen. Airflow was assessed using a thermistor and a pneumotachograph signal. These signals were recorded continuously on a polygraph (SleepLab® 1000P, Aequitron, MN, USA). Respiratory events were scored according to commonly used criteria, with apnoea defined as cessation of airflow lasting for $10 \mathrm{~s}$ or more and hypopnoea as a reduction in airflow or thoracoabdominal motion lasting $10 \mathrm{~s}$ or more, in association with an arousal or with a cyclical dip in $\mathrm{Sa}_{2} \mathrm{O}_{2}$. An arousal was defined according to the recommendations of American Sleep Disorders Association [14], as an abrupt shift in EEG frequency, which may include theta, alpha or frequencies greater than $16 \mathrm{~Hz}$, subject to various conditions. Microarousals were scored following the previous criteria but lasting at least $1.5 \mathrm{~s}$ and associated with EMG activity.

\section{Forced oscillation technique (FOT)}

The assessment of airway obstruction was carried out with the FOT by measuring $|Z|$, which is the quotient

Table 1. - Patient characteristics

\begin{tabular}{ccccccc}
\hline $\begin{array}{c}\text { Subject } \\
\text { No. }\end{array}$ & $\begin{array}{c}\text { Age } \\
\text { yrs }\end{array}$ & $\begin{array}{c}\text { Height } \\
\mathrm{cm}\end{array}$ & $\begin{array}{c}\text { Weight } \\
\mathrm{kg}\end{array}$ & $\begin{array}{c}\text { BMI } \\
\mathrm{kg} \cdot \mathrm{m}^{-2}\end{array}$ & $\begin{array}{c}\text { FEV1 } \\
\% \text { pred }\end{array}$ & AHI* \\
\hline 1 & 44 & 160 & 120 & 46 & 71 & 82 \\
2 & 54 & 171 & 88 & 30 & 109 & 42 \\
3 & 73 & 168 & 105 & 37 & 77 & 67 \\
4 & 42 & 177 & 118 & 37 & 86 & 76 \\
5 & 43 & 170 & 77 & 26 & 105 & 69 \\
6 & 47 & 170 & 90 & 31 & 77 & 81 \\
7 & 62 & 160 & 78 & 30 & 93 & 54 \\
\hline Mean \pm SD & $52 \pm 11$ & $168 \pm 6$ & $96 \pm 17$ & $34 \pm 6$ & $88 \pm 14$ & $67 \pm 14$ \\
\hline
\end{tabular}

*: values from baseline diagnostic polysomnogram; BMI: body mass index; FEV1: forced expiratory volume in one second; AHI: apnoea/hypopnoea index. between the amplitudes of oscillatory pressure and flow and represents the total mechanical load of the patient's respiratory system $[11,12]$. Therefore, increases in airway obstruction are accompanied by an increase in $|Z|$. Measurements in these patients were carried out using the setup shown in figure 1. A CPAP nasal mask which incorporated a naso-oral thermistor was connected to a pneumotachograph (dead space: $22 \mathrm{~mL}$ ) and this was connected to a T-piece. One arm of this T-piece was connected to a chamber with a loudspeaker (JBL-800GTI, 8" subwoofer, $600 \mathrm{~W}$; SBL, Victoria, Spain) and the other arm to a tube acting as a pneumatic low-pass filter. In order to avoid rebreathing, a continuous flow $\left(0.3 \mathrm{~L} \cdot \mathrm{s}^{-1}\right)$ of fresh air was passed along the tube (fig. 1). An oscillating pressure of small amplitude $\left(1.5 \mathrm{cmH}_{2} \mathrm{O}\right.$ peak-to-peak) was generated by the loudspeaker while the patient breathed spontaneously. The oscillation frequency was set at $5 \mathrm{~Hz}$ since in a model study [12] we found that this frequency optimized the sensitivity of the system to obstruction as well as time resolution. Nasal pressure $\left(P_{n}\right)$ and flow $\left(V^{\prime} n\right)$ were measured by differential pressure transducers (MP 45; Validyne Co, Northridge, CA, USA). $P$ n and $V^{\prime}$ n were analogically low-pass filtered (Butterworth, 8 poles, 16 $\mathrm{Hz}$ cutoff frequency) and fed into an analogue circuit that provided continuous estimation of $|Z|$. This analogue circuit mimicked the digital signal processing to compute $|Z|$ as described previously in detail [12]. The analogue signal corresponding to $|Z|$ was fed into an auxiliary channel of the polygraph in addition to the other PSG data.

To perform a more detailed analysis of the FOT signals, $P \mathrm{n}, V^{\prime} \mathrm{n}$ and $|Z|$ were acquired simultaneously at a frequency of $100 \mathrm{~Hz}$ by an independent computerized system (CODAS; DATAQ Instruments Inc., Akron, OH, USA) and stored for subsequent analysis. Synchronization marks allowed association of the signals recorded by the two independent acquisition systems. Before the beginning of the study, and after the calibration procedures were carried out with the patient awake in the recumbent position and with all the equipment connected, we carefully fitted the nasal mask to minimize leaks. To this end, we applied CPAP of $5 \mathrm{cmH}_{2} \mathrm{O}$ with an external device, the patient was

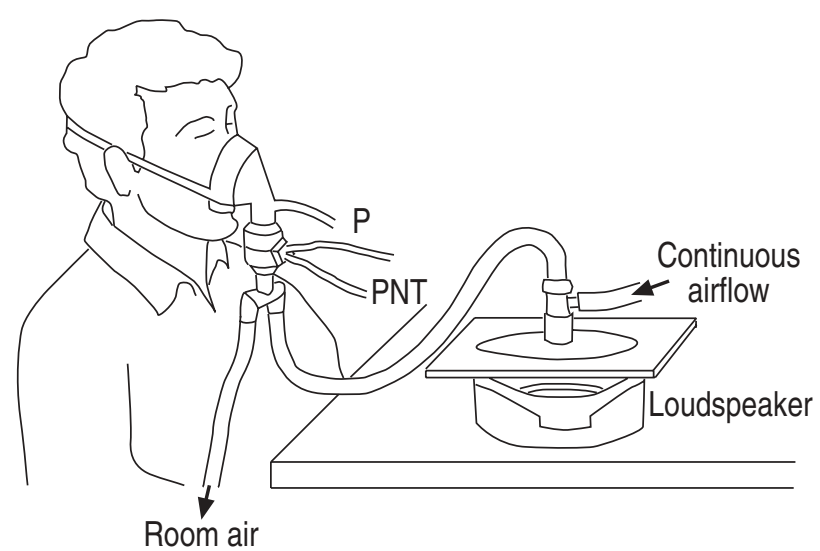

Fig. 1. - Experimental setup. Subjects breathed through a nasal mask connected to a pneumotachograph and a unidirectional valve. A loudspeaker that generated a continuous sinusoidal signal at a frequency of 5 $\mathrm{Hz}$ was connected to the patient. To avoid rebreathing, a continuous flow of air was generated. the other side of the unidirectional valve was connected to a $1 \mathrm{~m}$ tube (diameter $2 \mathrm{~cm}$ ) thus avoiding the leak of the sinusoidal signal generated. See text for further explanation. P: pressure signal; PNT: pneumotachograph. 


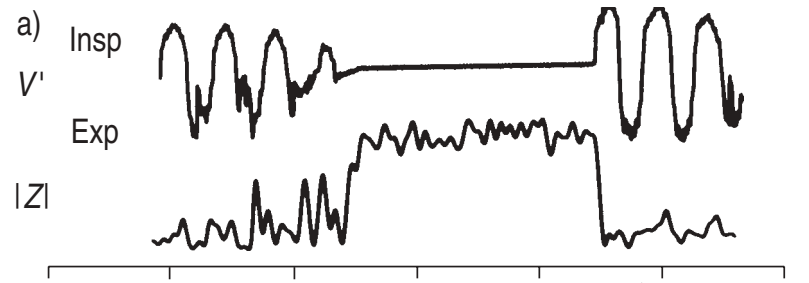

b)

b) Insp

$V^{\prime}$

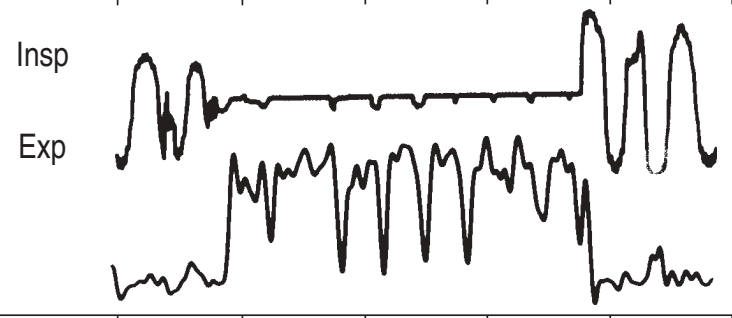

$|Z|$ $\operatorname{Exp}$

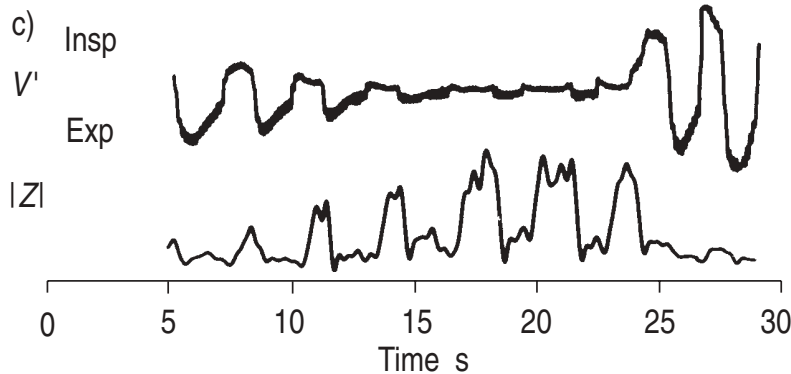

Fig. 2. - Examples of the three different patterns of oscillatory airway impedance $(|Z|)$ and flow $\left(V^{\prime}\right)$ during respiratory events. a) corresponds to an apnoea with a corresponding persistent increase of $|Z|$ observed throughout the apnoea. (b) and c) depict two different hypopnoeas with corresponding intermittent patterns in $|Z|$. In the first hypopnoea $b$ ), high $|Z|$ values are interrupted by intermittent decreases during expiration (Exp.) whereas (c) shows normal $|Z|$ values, followed by intermittent increases during inspiration (Insp.). required to stop breathing for a brief period and, if necessary, adjustments of the mask were made until the leak with $\mathrm{CPAP}=5 \mathrm{cmH}_{2} \mathrm{O}$ was $<50 \mathrm{~mL} \cdot \mathrm{s}^{-1}$. With such a procedure we increased the resistance of the leak, which is placed in parallel to the patient, to a value of $>100$ $\mathrm{cmH}_{2} \mathrm{O} \cdot \mathrm{L}^{-1} \cdot \mathrm{s}$ and thus, we optimized the sensitivity of the method to assess airway obstruction $[12,15]$.

\section{Protocol and data analysis}

In each subject, after a well-established sleep phase was achieved, at least $1 \mathrm{~h}$ of sleep was recorded including the polysomnographic variables previously described plus the continuous measurement of $|Z|$. The stored data were analysed in two separate steps at random. First, we scored sleep and respiratory variables from the polysomnographic computer-displayed tracings but without visualizing the channel assigned to $|Z|$ following the criteria described above. Second, visualizing only $|Z|$ on the screen, we scored respiratory events in terms of a persistent or intermittent increase in $|Z|$ lasting $>10 \mathrm{~s}$ and exhibiting phasic changes.

A further analysis was carried out to check the concordance between the respiratory events detected by conventional criteria from PSG and those by the FOT. Finally, we selected at random 20 respiratory events for measuring the mean value of $|Z|$ and analysed their characteristics (i.e. persistent or intermittent increases in $|Z|$, occurrence during inspiration or expiration) and changes preceding apnoeas. Data are expressed as mean \pm SD. Comparison between the events scored by classical PSG and FOT were compared using the method of Bland and Altman [16]. Statistical significance was defined as $\mathrm{p}<0.05$.

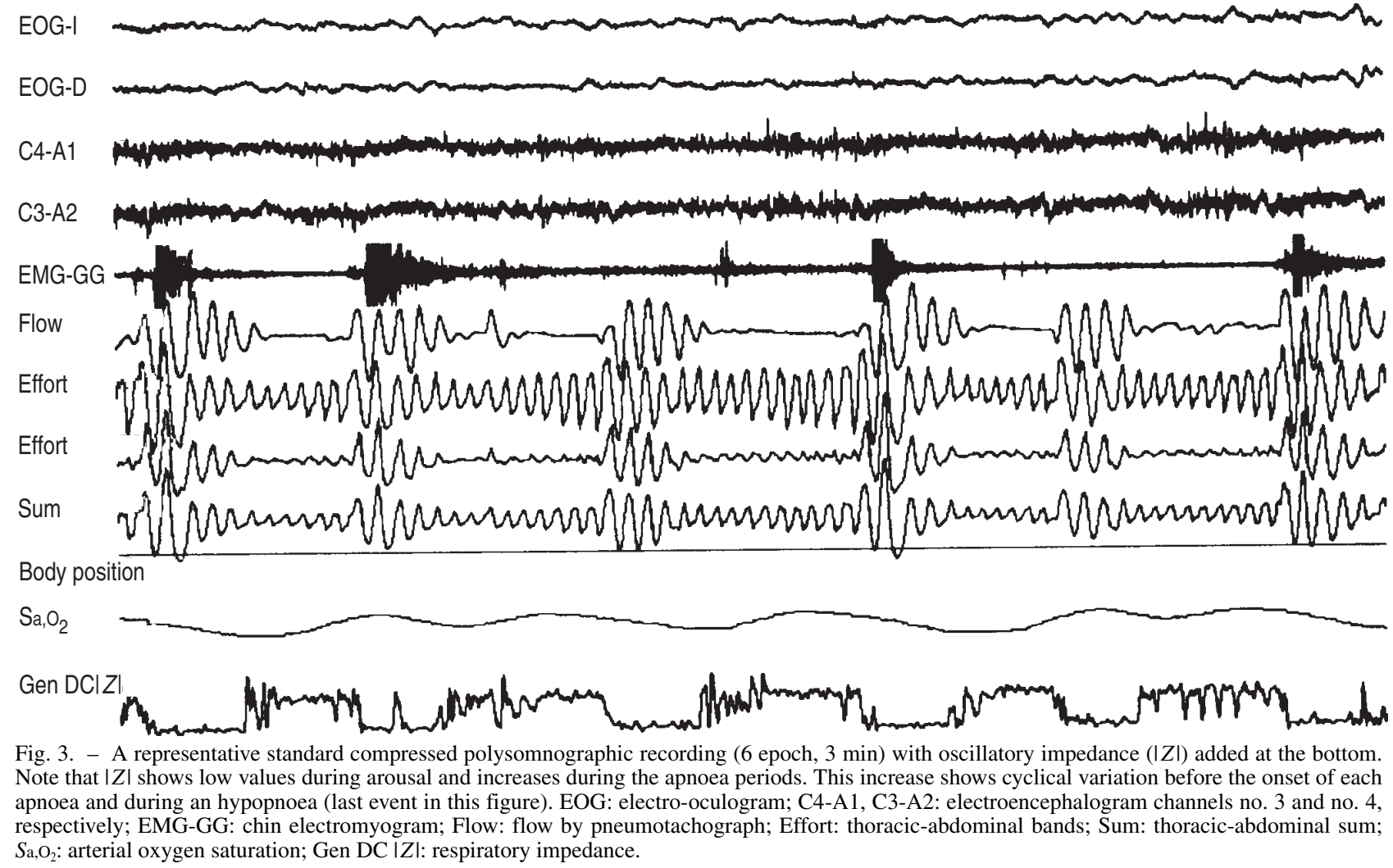




\section{Results}

In this study in patients with severe SAHS, FOT was easily applied since only a CPAP mask and a loudspeaker were required. The setup was well tolerated during all the nap periods. Moreover, superimposing a $5 \mathrm{~Hz}$ oscillation on the circuit in an on/off manner did not elicit changes in the EEG during stable sleep.

Initial analysis showed three distinct impedance patterns which corresponded with respiratory events - obstructive apnoea and hypopnoea-registered by the conventional app- roach (fig. 2). In figure $2 \mathrm{a}$, an apnoea is observed from the airflow signal with a corresponding persistent increase in $|Z|$ maintained throughout. Figure $2 \mathrm{~b}$ and $\mathrm{c}$ shows two hypopnoeas that are accompanied by transient changes in $|Z|$. However, the behaviour of $|Z|$ during these two hypopnoeas is different. Figure $2 \mathrm{~b}$ shows a hypopnoea with an increase in $|Z|$ value with accompanying periods of reduction in $|Z|$ during short periods of expiration; by contrast, figure $2 \mathrm{c}$ shows baseline low $|Z|$ values with periodic increases during inspiration.

EOG-I

EOG-D

C4-A1

C3-A2

EMG-GG

Flow

Effort

Effort

Sum

Body position

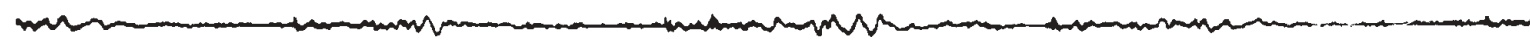

$\mathrm{Sa}, \mathrm{O}_{2}$

Gen DC |Z|

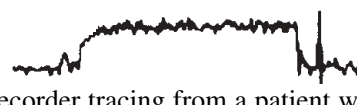

Fig. 4. - Recorder tracing from a patient with predominantly central apnoeas. During central apnoeas, airway impedance showed either high or low $|Z|$ values. For definitions, see legend to figure 3.
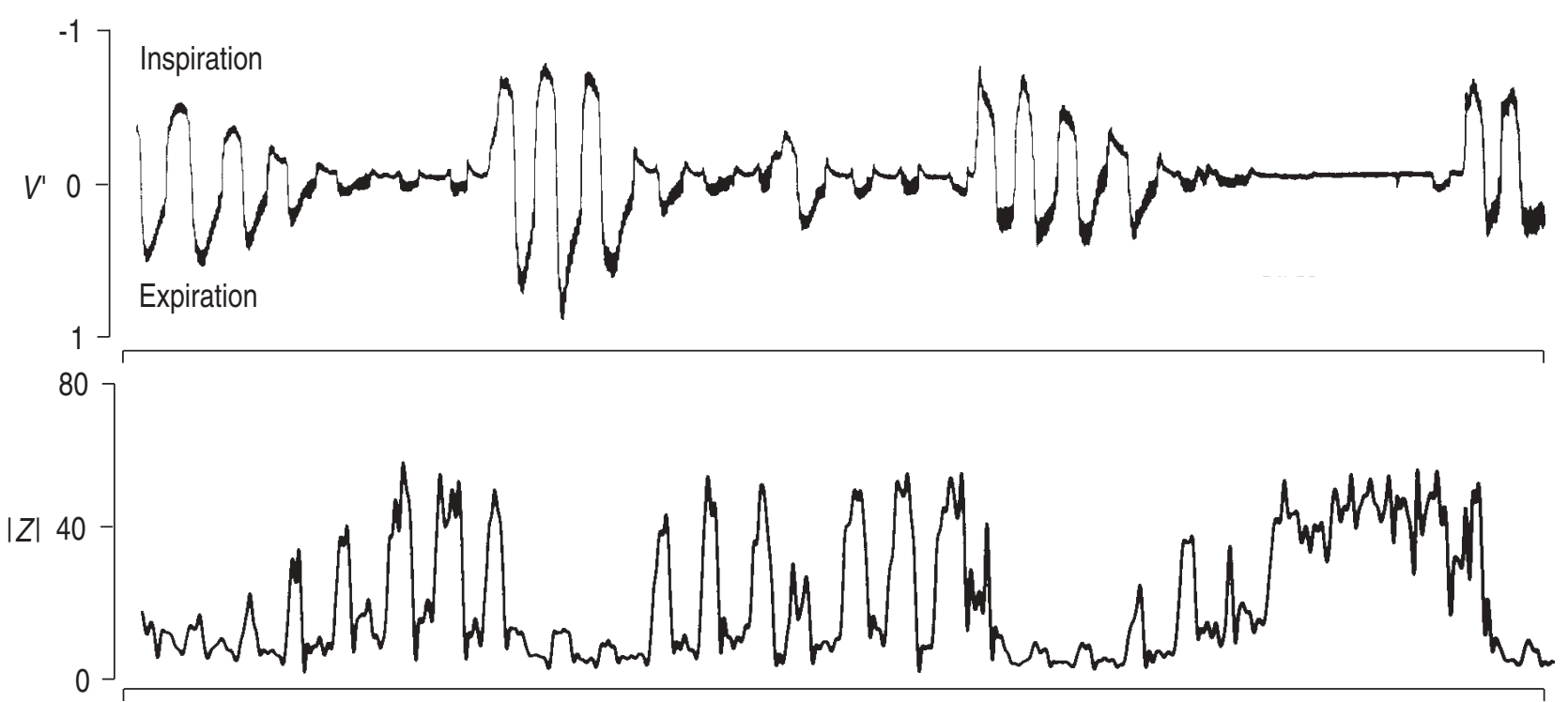

$80 \mathrm{~s}$

Fig. 5. - A representative example of hypopnoeas in Stage 2 sleep. Note that during the hypopnoea transient increases in the amplitude of impedance $(|Z|)$ during inspiration that correspond to limitation of inspiratory airflow in the pneumotachograph signal. During the apnoea (last event of the figure) the increase in $|Z|$ was sustained. $V^{\prime}$ : flow. 
The addition of $|Z|$ to the conventional polysomnographic display is shown in figure 3. In general, $|Z|$ shows low (normal) values during wakefulness or during periods of increased ventilation associated with arousals but marked and sustained increases during the apnoeas. These increases were systematically preceded by irregular variation in $|Z|$ shortly before the beginning of apnoeas and during certain hypopnoeas (see last event in fig. 3).

Figure 4 displays a compressed PSG tracing in a patient with typical central apnoeas. Here, two additional $|Z|$ patterns were observed with high or low $|Z|$ values suggesting different mechanisms involved.

Figure 5 shows detailed examples of the behaviour of $|Z|$ during apnoeas and hypopnoeas. Note that during hypopnoeas, $|Z|$ increases during inspiration and decreases during expiration. During the apnoea the increase in $|Z|$ was sustained.
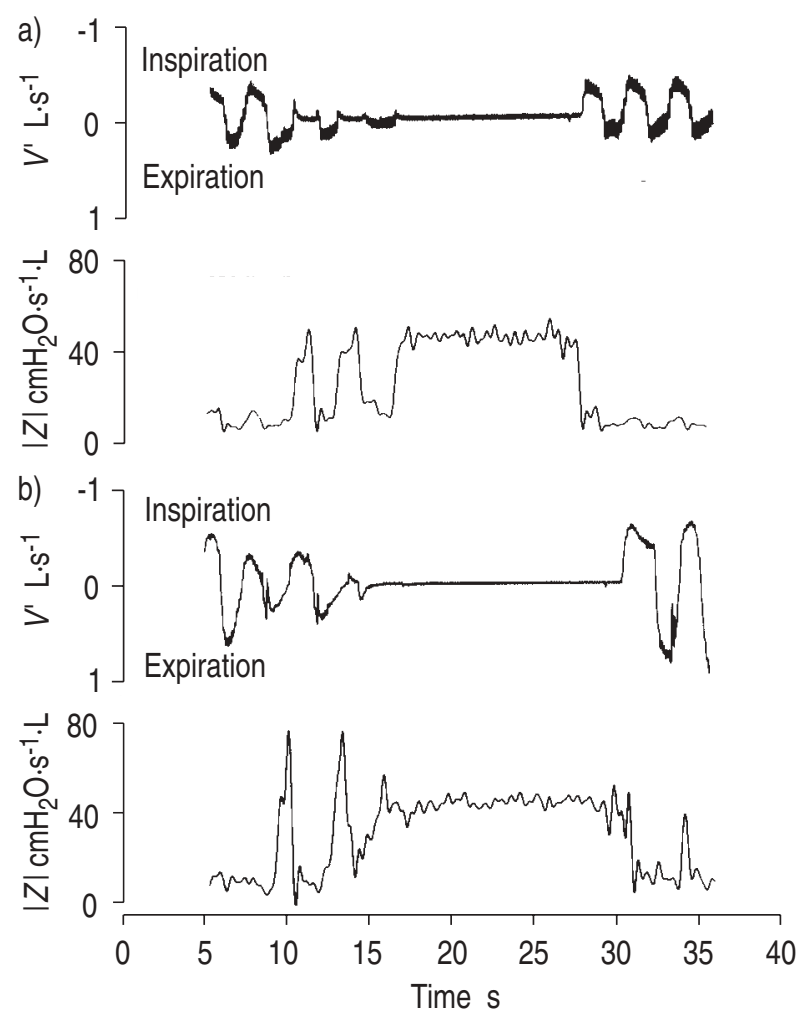

Fig. 6. - Representative examples of an apnoea in Stage 2 sleep. a) shows transient increases in the amplitude of impedance $(|Z|)$ during inspiration coincident with limited inspiratory flow before apnoea ensues. b) shows transient increases in $|Z|$ that occur during expiration. $V^{\prime}$ : flow.

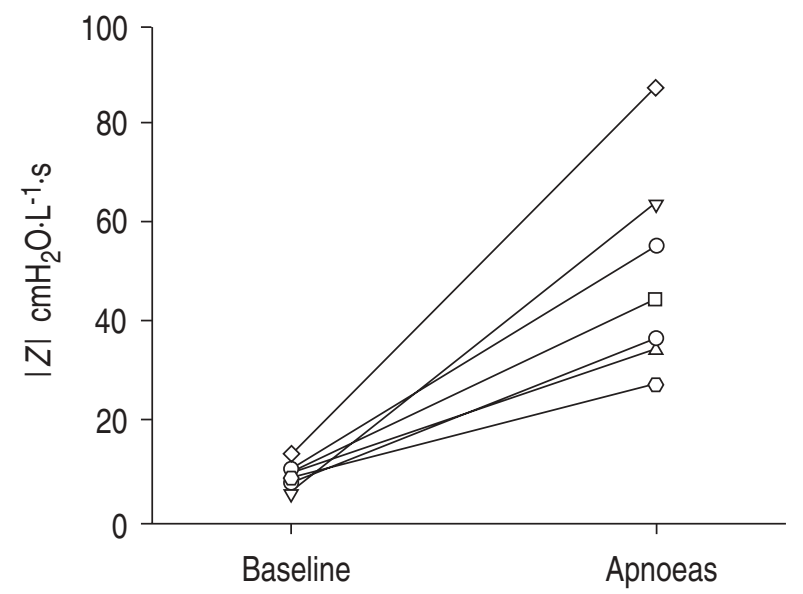

Fig. 7. - The amplitude of impedance ( $|Z|)$ values at baseline and during apnoeas for the seven patients.

Figure 6a displays transient increases in $|Z|$ during inspiration before the onset of apnoea and Figure $6 \mathrm{~b}$ displays transient increases in $|Z|$ during expiration before apnoea onset. Before apnoea onset, four individuals developed transient increases in $|Z|$ at the end of expiration, whereas in two patients the increases in $|Z|$ occurred during inspiration.

Table 2 shows the characteristics of $|Z|$ and the respiratory events obtained. The mean \pm SD number of respiratory events detected with conventional full PSG (55 \pm 16 ; and by the FOT $(58 \pm 17)$ were similar with no statistical differences. In addition, the time-related concordance between the respiratory events detected by PSG and FOT was entirely accurate. The mean number of arousals detected during the study period in the seven patients was $53 \pm 16$.

Figure 7 shows the $|Z|$ values at baseline $\left(11 \pm 4 \mathrm{cmH}_{2} \mathrm{O}\right.$. $\left.\mathrm{L}^{-1} \cdot \mathrm{s}\right)$ with increases during the apnoeas $\left(50 \pm 20 \mathrm{~cm} \mathrm{H}_{2} \mathrm{O}\right.$. $\mathrm{L}^{-1} \cdot \mathrm{s}$ ) in all but one patient (the one with a central apnoea).

\section{Discussion}

This study shows that, in patients with severe SAHS during a nap study, $|Z|$, a quantitative index of airway obstruction, is a potential alternative or complementary method for the diagnosis of respiratory events. Accordingly, we found a high degree of correspondence in detection of respiratory events between conventional means and the FOT. In addition, we observed that this technique applied during sleep is well tolerated, being easily added

Table 2. - Respiratory events and characteristics of FOT data obtained during the nap PSG

\begin{tabular}{cccccc}
\hline $\begin{array}{c}\text { Subject } \\
\text { No. }\end{array}$ & $\begin{array}{c}\text { Respiratory events } \\
\text { detected by PSG } \\
\mathrm{n}\end{array}$ & $\begin{array}{c}\text { Arousals } \\
\mathrm{n} \cdot \mathrm{h}^{-1}\end{array}$ & $\begin{array}{c}\text { Respiratory events } \\
\text { detected by FOT }\end{array}$ & Mean \pm SD $|Z|$ & Time of increase of $|Z|$ \\
\hline 1 & 63 & 52 & 67 & $37 \pm 2$ & End-expiration \\
2 & 53 & 50 & 51 & $45 \pm 5$ & Inspiration \\
3 & 65 & 61 & 67 & $35 \pm 6$ & End-expiration \\
4 & 75 & 49 & 81 & $64 \pm 6$ & End-expiration \\
5 & 42 & 65 & 45 & $28 \pm 2$ & Inspiration \\
6 & 65 & 27 & 67 & $56 \pm 9$ & Inspiration and end-expiration \\
7 & 27 & $53 \pm 16$ & 29 & $50 \pm 20$ & \\
\hline Mean \pm SD & $55 \pm 16$ & $58 \pm 17$ &
\end{tabular}

FOT: forced oscillation technique; PSG: polysomnography; $|Z|$ : oscillatory impedance. 
to the conventional sleep setup. Moreover, it provides an on-line quantitative approach for continuous monitoring of airway mechanics during sleep.

Although FOT has been applied in respiratory medicine during the past few years $[17,18]$, only preliminary data obtained during sleep have been reported $[19,20]$. The interpretation of obstruction indices measured by FOT during apnoea and hypopnoea required a model investigation since flow-limitation and dynamic occlusion is present in the collapsible upper airway of patients with SAHS. In a previous study, our group analysed and tested the suitability of FOT in a model and concluded that the technique is appropriate for assessing airway obstruction under dynamic airflow conditions found in SAHS [12]. $|Z|$ is computed from nasal pressure and flow and therefore, the impedance measured corresponds to that of the total respiratory system. As in SAHS patients the most relevant mechanical abnormality is in the upper airway, the patterns of change in $|Z|$ illustrated in figure 2 can be attributed mainly to variation in the degree of upper airway obstruction.

In this preliminary report, the FOT has enabled us to make some interesting observations on the patterns of airway obstruction during apnoea and hypopnoea and on the changing airway resistance and its timing immediately before each apnoea or hypopnoea. In addition, the method gives an insight into the pathophysiology of SAHS. Indeed, when apnoea occurs there is a corresponding increase in $|Z|$ that is sustained as a plateau until apnoea terminates following arousal. The different values of $|Z|$ corresponding to obstructive apnoeas (i.e., total occlusion) (fig. 7) correspond to the distensibility of the upper airway upstream from the occlusion site and to possible leaks in the mask [12]. During hypopnoeas different intermittent patterns of obstruction were observed (fig. 2). We have also noticed that, in most patients, the beginning of an apnoea is preceded by brief obstructions, mainly during expiration, while during hypopnoeas, obstructive periods are mainly inspiratory. The significance of these observations needs, however, to be further investigated. We therefore consider that FOT may be a potentially useful and powerful method for the noninvasive recognition of even subtle mechanical events associated with respiratory disturbances during sleep (i.e. the so-called "upper airway resistance syndrome").

In the present study, we applied the FOT with a setup similar to that used for CPAP treatment, thus minimally disturbing the subject. With the oscillation frequency applied $(5 \mathrm{~Hz})$ in an on/off manner, sleep was not disturbed as shown by the unchanged EEG (no arousals nor microarousals) and chin EMG. More studies are required to investigate other amplitudes and frequencies but it appears that with the low-frequency $(5 \mathrm{~Hz})$, low-pressure $(1.5$ $\mathrm{cmH}_{2} \mathrm{O}$ ) oscillations applied in our study, reflex activity such as may occur when high frequencies $(30 \mathrm{~Hz})$ are applied [21], is not present. However, more sophisticated EEG analysis or needle EMG of muscle subgroups during low-frequency oscillation might clarify this point further. One possible practical concern is the application of FOT in the presence of mask leaks. As required whenever any system or device is employed to achieve quantitative flow measurements (i.e. pneumotachograph), leaks should be reduced as much as possible $[12,15]$.
In conclusion, this pilot study demonstrates that the forced oscillation technique is a clinically useful tool for noninvasive assessment of recurrent obstruction of the collapsible upper airway of patients with sleep apnoea/ hypopnoea syndrome. In addition, the technique may give further pathophysiological information to assess upper airway behaviour, hence strengthening the usefulness of correlation studies in which the timing of respiratory events can be critical. It is important now to proceed to studies involving the whole night and to include patients with milder sleep apnoea/hypopnoea syndrome or other conditions accompanied by upper airway narrowing, such as nonapnoeic snoring.

\footnotetext{
Acknowledgements: The authors are grateful to A. Reolid for her technical assistance, to the nurses of the respiratory ward for their unselfish co-operation and J.R. Kimoff for his criticisms and helpful suggestions.
}

\section{References}

1. Remmers JE, DeGroot WJ, Sauerland EK, Anch AM. Pathogenesis of upper airway occlusion during sleep. $J$ Appl Physiol 1978; 44: 931-938.

2. White PD. Pathophysiology of obstructive sleep apnoea. Thorax 1995; 50: 797-804.

3. Kimoff RJ, Cheong TH, Olha AE, et al. Mechanisms of apnoea termination in obstructive sleep apnoea: role of chemoreceptor $v s$ mechanoreceptor stimuli. Am J Respir Crit Care Med 1994; 149: 707-714.

4. Gould GA, Whyte KF, Rhind GB, et al. The sleep hypopnoea syndrome. Am Rev Respir Dis 1988; 137: 895898.

5. Whyte KF, Allen MB, Fitzpatrick MF, Douglas NJ. Accuracy and significance of scoring hypopnoeas. Sleep 1992; 15: $257-260$

6. Stoohs R, Skrobal A, Guilleminault C. Does snoring intensity predict flow limitation or respiratory effort during sleep? Respir Physiol 1993; 92: 27-38.

7. Montserrat JM, Ballester E, Olivi H, et al. Time-course of stepwise titration. Am J Respir Crit Care Med 1995; 152 : 1854-1859.

8. Guilleminault C, Stoohs R, Clerk A, Cetel M, Maistros P. A cause of excessive daytime sleepiness. The upper airway resistance syndrome. Chest 1993; 104: 781787.

9. Condos R, Norman RG, Krishnasamy I, Peduzzi N, Goldring RM, Rapoport DM. Flow limitation as a noninvasive assessment of residual upper-airway resistance during continuous positive airway pressure therapy of obstructive sleep apnoea. Am J Respir Crit Care Med 1994; 150: 475-480.

10. Tvinnereim M, Mateika S, Cole P, Haight J, Hoffstein V. Diagnosis of obstructive sleep apnoea using a portable transducer catheter. Am J Respir Crit Care Med 1995; 152: 775-779.

11. Peslin R, Fredberg JJ. Oscillation mechanics of the respiratory system. In: Handbook of Physiology. Vol. 3, Part I. Bethesda, MD, Amer. Physiol. Soc 1986; pp. 145179.

12. Farré R, Peslin R, Rotger M, Navajas D. Inspiratory dynamic obstruction detected by forced oscillation during CPAP. A model study. Am J Respir Crit Care Med 1997; 
155: 952-956.

13. U.S. Public Health Service. Rechtschafen A, Kales A, eds. A Manual of Standardized Terminology, Techniques and Scoring System for Sleep Stages of Human Subjects. Washington, DC, U.S. Government Printing Office.

14. ASDA report. EEG arousals: scoring rules and examples. Sleep 1992; 15: 174-184.

15. Farré R, Rotger M, Montserrat JM, Navajas D. System to generate forced oscillation superimposed to continuous positive airway pressure. Eur Respir J 1997; 10: 1349_ 1353.

16. Bland JM, Altman DG. Statistical methods for assessing agreement between two methods of clinical measurement. Lancet 1986; 1: 307-310.

17. Navajas D, Farré R, Rotger M, Torres A. Monitoring respiratory impedance by forced oscillation in mechani- cally-ventilated patients. Eur Respir Rev 1994; 4: 216-218.

18. Farré R, Peslin R, Rotger M, Navajas D. Human lung impedance from spontaneous breathing frequencies to 32 Hz. J Appl Physiol 1994; 76: 1176-1183.

19. Schlenker E, Kirchheiner T, Rühle KH. Oscillatory impedance. A new method to detect upper airway obstruction during sleep (abstract). Am J Respir Crit Care Med 1995; 151: A251.

20. Schlenker E, Kirchheiner T, Rühle KH. Oesophageal pressure and thoraco-abdominal movement versus oscillatory impedance to detect upper airway obstruction in sleep apnoea syndrome (abstract). Eur Respir J (Suppl. 19). 23: $255 \mathrm{~s}$.

21. Henke KG, Sullivan CE. Effects of high-frequency oscillating pressures on upper airway muscles in humans. $J$ Appl Physiol 1993; 75: 856-862. 